\title{
Inferring Amazon leaf demography from satellite observations of leaf area index
}

\author{
S. Caldararu ${ }^{1}$, P. I. Palmer ${ }^{1}$, and D. W. Purves ${ }^{2}$ \\ ${ }^{1}$ School of GeoSciences, University of Edinburgh, Edinburgh, UK \\ ${ }^{2}$ Microsoft Research, Cambridge, UK \\ Correspondence to: S. Caldararu (s.caldararu@sms.ed.ac.uk)
}

Received: 25 September 2011 - Published in Biogeosciences Discuss.: 25 October 2011

Revised: 20 March 2012 - Accepted: 27 March 2012 - Published: 16 April 2012

\begin{abstract}
Seasonal and year-to-year variations in leaf cover imprint significant spatial and temporal variability on biogeochemical cycles, and affect land-surface properties related to climate. We develop a demographic model of leaf phenology based on the hypothesis that trees seek an optimal leaf area index (LAI) as a function of available light and soil water, and fit it to spaceborne observations of LAI over the Amazon basin, 2001-2005. We find the model reproduces the spatial and temporal LAI distribution whilst also predicting geographic variation in leaf age from the basin centre ( $2.1 \pm 0.2$ years), through to the lowest values over the deciduous eastern and southern Amazon (6士2 months). The model explains the observed increase in LAI during the dry season as a net addition of leaves in response to increased solar radiation. We anticipate our work to be a starting point from which to develop better descriptions of leaf phenology to incorporate into more sophisticated earth system models.
\end{abstract}

\section{Introduction}

Seasonal and year-to-year variations in leaf area imprint significant spatial and temporal variability on biogeochemical cycles and affect land-surface properties related to climate (Hayden, 1998). For example, the transfer of water from the soil to the atmosphere is mostly via leaves through evapotranspiration, subsequently affecting humidity, air temperature and rainfall (Wilson and Baldocchi, 2000). Similarly, carbon enters vegetated ecosystems through carbon fixation via photosynthesis (White et al., 1999).

Over temperate regions leaf phenology is known to be driven by changes in day length and temperature (Schwartz,
1999), although the relative importance of these determining factors and how they might change with climate is poorly understood (Korner and Basler, 2010).

However, the majority of the world's forests retain leaves year round: boreal forests which are dominated by evergreen needle-leaf trees and often mixed with deciduous broadleaf and needle-leaf species; and mesic tropical forests, dominated by evergreen broadleaf species, which are responsible for the majority of terrestrial carbon fixation (Malhi and Grace, 2000). Observed LAI over these evergreen forests, particularly over the tropics, still show seasonal and yearto-year variations (Myneni et al., 2007), but we lack knowledge about the magnitude, geography, timing, and the processes driving such variation, partly reflecting the difficulty of taking year-round measurements. Consequently many modelling studies assume that tropical leaf area is constant (Cramer et al., 2001; Arora and Boer, 2005).

Space-borne observations of LAI offer the best opportunity to develop a quantitative model of large-scale controls of leaf area by virtue of their frequency and global coverage. We focus our study on the Amazon basin $\left(10^{\circ} \mathrm{N}-10^{\circ} \mathrm{S}\right.$, $\left.80^{\circ} \mathrm{W}-50^{\circ} \mathrm{W}\right)$. The vegetation in the region is mainly semideciduous or evergreen tropical forest, but the species composition varies widely due to the differences in soil type and altitude across the basin (Sombroek et al., 2000).

The Amazon basin experiences wet and dry seasons, with the dry season generally running from June-September, with longer and drier periods in the south-eastern regions (Sombroek, 2001). Fig. 1 shows that the timing of low precipitation coincides with an increase in direct radiation mainly due to a decrease in cloud cover. Levels of diffuse radiation are comparatively constant throughout the year. 
DJF
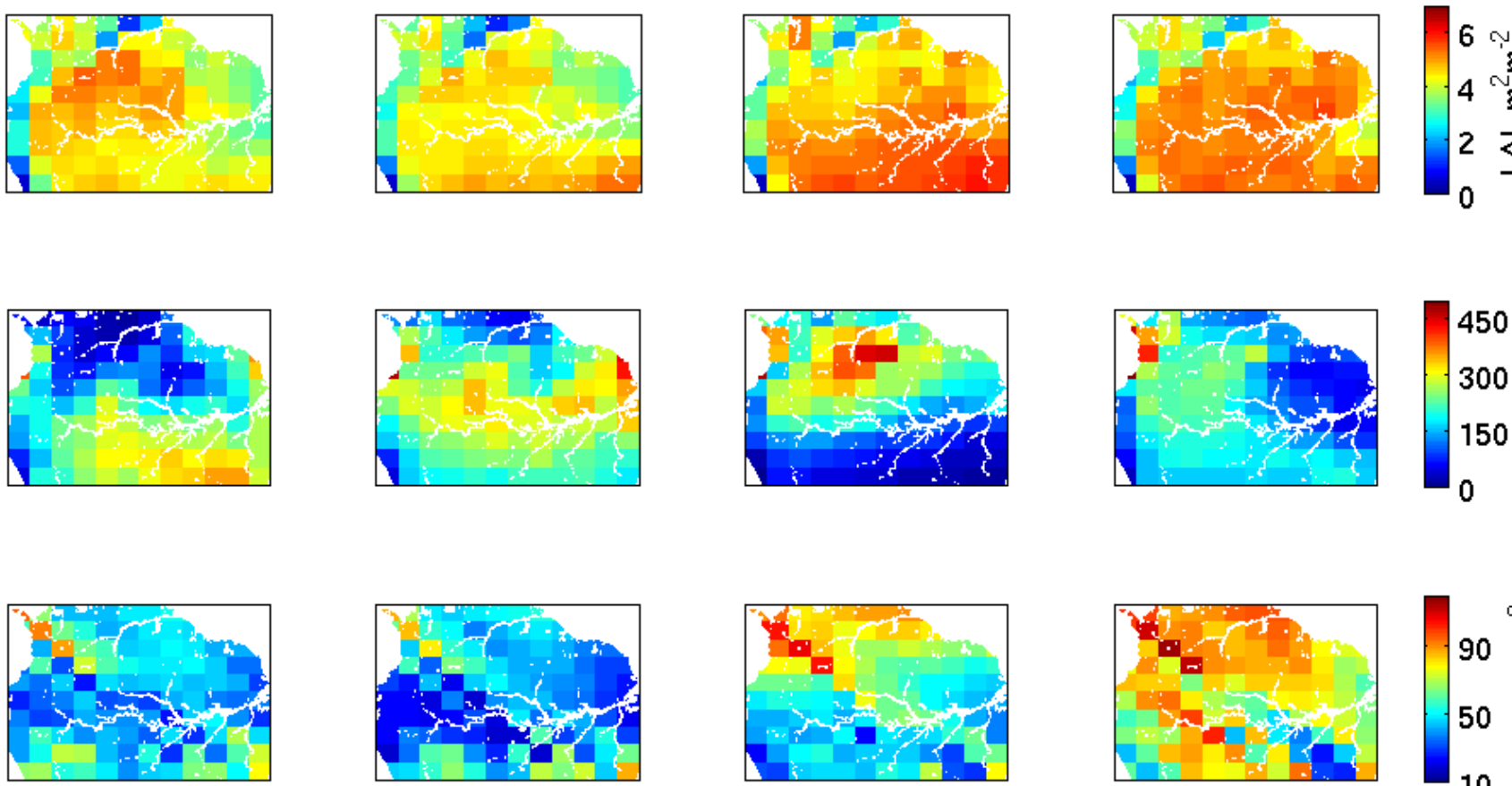

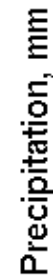
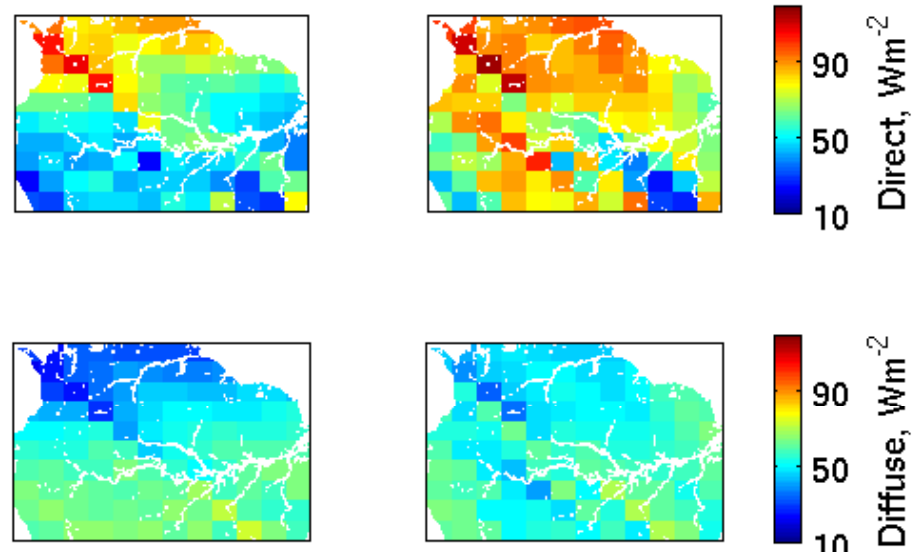

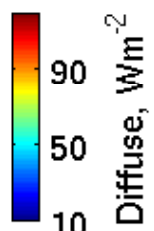

$\frac{E}{3}$
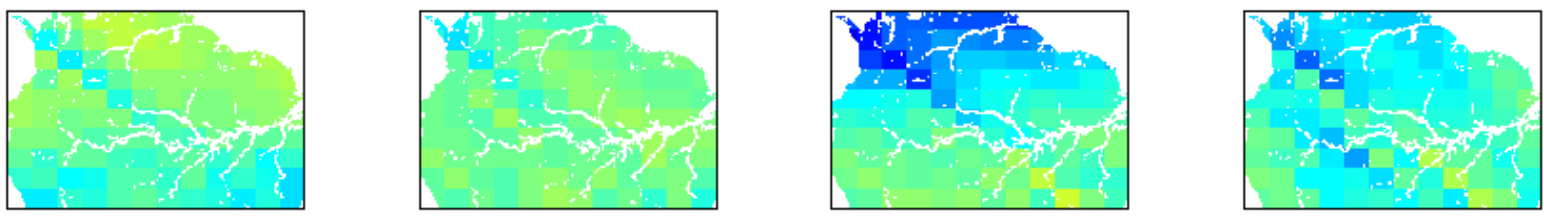

Fig. 1. From top to bottom: MODIS leaf area index $\left(\mathrm{m}^{2} \mathrm{~m}^{-2}\right)$, WorldClim precipitation (mm) (Hijmans et al., 2005), GEOS-4 direct and diffuse photosynthetically active radiation, PAR $\left(\mathrm{Wm}^{-2}\right)$ across the study region. The dry season, with precipitation levels of under $100 \mathrm{~mm}$, runs generally from July-September, period which coincides with an increase in direct PAR due to a decrease in cloud cover. We can observe that the LAI also peaks during this period, reaching its lowest levels in the wet season.

Ground-based studies have reported an increase in leaf litterfall during the dry period (Malhado et al., 2009; Chave et al., 2010), but without simultaneous measurements of leaf gain we cannot determine whether the increased litterfall represents a net loss of leaves. Studies using space-borne vegetation data (Myneni et al., 2007; Huete et al., 2006) have reported an increase in greenness during the dry season over the Amazon, even during severe droughts (Saleska et al., 2007), but these drought observations have been disputed (Samanta et al., 2010; Doughty and Goulden, 2008). These observations are consistent with indirect evidence from the seasonal cycle of satellite-observed emission of biogenic trace gases (Barkley et al., 2009). The dry-season increase in leaf area could be explained by soil moisture dynamics: water is available all year round in the deeper soil layers (Harper et al., 2010), which can be readily accessed by the large rooting depths of Amazonian vegetation (Nepstad et al., 1994;
Jipp et al., 1998). Under these circumstances, we expect that light availability is the primary controlling factor for determining changes in leaf area (Wright and Vanschaik, 1994). This implies that trees will carry more leaves in the dry season when direct radiation is greater. To test this idea and to enable predictive modelling of Amazon leaf phenology, we develop a simple leaf phenology model for the Amazon tropical forest. Sect. 3 describes this model, which we fit to MODIS LAI data (Sect. 2) to obtain parameter values for the Amazon basin. We discuss our results in Sect. 4 and demonstrate how, in principle, our predictions of leaf area and age distribution could impact carbon assimilation using a simple carbon model. We conclude our paper in Sect. 5. 


\section{Data sets used}

\subsection{MODIS LAI data}

We use leaf area index (LAI) data obtained from the MODIS (Moderate Resolution Imaging Spectroradiometer) instrument aboard the NASA Terra platform. The LAI/fPAR (fraction of absorbed photosynthetically active radiation) product collection 5 (MOD15A2) is available globally at a spatial resolution of $1 \mathrm{~km}$ every 8 days for the period 2000-present and has been downloaded from https://lpdaac.usgs.gov/. The 8 day temporal resolution is a result of compositing, i.e. assigning the best value for the 8 day period based on maximum fPAR. The data set is split into tiles $\left(10^{\circ}\right.$ latitude by $10^{\circ}$ longitude at the equator), which cover northern South America and include the Amazon basin. We use tiles h10-12v08 and h10-12v09 for the years 2001 to 2005 .

The LAI is calculated using a radiative transfer algorithm (the main algorithm), which uses the red $(648 \mathrm{~nm})$ and nearinfrared $(858 \mathrm{~nm})$ bands. The algorithm uses biome-specific vegetation structure and height, leaf type and soil brightness to obtain LAI values (Yang et al., 2006; Knyazikhin et al., 1997, 1999). In conditions where the main algorithm cannot be applied, a back-up algorithm is used, in which case the LAI value is calculated using an empirical relationship between Normalised Difference Vegetation Index (NDVI) and LAI. The data quality is affected by the presence of cloud, atmospheric aerosol loading and snow cover. Snow cover is not an issue for our study region, but cloud cover can affect the quality of the data, especially during the wet season, while aerosols from biomass burning can interfere with measurements during the dry season. The quality flags provided along with the LAI data offer information on overall data quality, the algorithm used, cloud cover and aerosol presence. Ground validation studies (Cohen et al., 2006) have shown that the back-up algorithm is often unreliable and our analysis of the data over the Amazon region shows that values assigned by the backup algorithm are often unrealistically low, leading to large week-to-week swings in LAI. As a consequence, we remove any LAI values calculated using the back-up algorithm prior to spatial averaging.

LAI retrievals of vegetation often have saturation problems in that LAI becomes insensitive to changes in reflectance. Studies have shown that this was an issue for high-biomass areas for collections 3 and 4, but this has been considerably improved for collection 5 (Yang et al., 2006). Ground based values of LAI in the Amazon basin range from 3.5-6 $\mathrm{m}^{2} \mathrm{~m}^{-2}$ (Malhado et al., 2009; Aragão et al., 2005; Roberts et al., 1996; Meir et al., 2000), with values of up to $10 \mathrm{~m}^{2} \mathrm{~m}^{-2}$ registered by some studies (Doughty and Goulden, 2008), with differences arising from the different measurement methods. MODIS LAI values are in the range 2-6 $\mathrm{m}^{2} \mathrm{~m}^{-2}$, which provides us with some confidence that there are no major saturation problems.
When relating leaf reflectance measurements to seasonal cycles we must take into account the fact that changes in observed reflectance can also be caused by changes in the number of young leaves, as these have different reflectance properties. This has been advanced as an explanation for the observed seasonal swings over the Amazon basin by several studies (Doughty and Goulden, 2008; Asner and Alencar, 2010; Aragão et al., 2009; Brando et al., 2010). However, the observed seasonal changes in LAI are too large to be attributed to a flush of new leaves only (Samanta et al., 2012).

The study region includes lowland tropical forests, alpine forests, savannas and grasslands. As our study is focused on forests, we use the MODIS landcover product MOD12Q1 to filter non-forested pixels. We use the provided IGBP classification scheme and have retained only pixels in classes $1-$ 5 , evergreen needleleaf forest, deciduous needleleaf forests, deciduous broadleaf forest, evergreen broadleaf forest and mixed forest. As there is no way to distinguish between lowland and alpine forests we include both in our analysis.

We reproject the LAI data to an orthogonal projection and average it to the resolution of the GEOS-4 PAR data $\left(2^{\circ}\right.$ latitude and $2.5^{\circ}$ longitude) and subsequently fit our model at this resolution.

\subsection{Radiation data}

We use photosynthetic active radiation (PAR) fields from assimilated meteorological data products of the Goddard Earth Observing System (GEOS-4) based at the NASA Global Modeling and Assimilation Office (GMAO) (Bey et al., 2001). The temporal resolution of this data is 1 day and the spatial resolution is $2^{\circ} \times 2.5^{\circ}$.

\subsection{Soil moisture data}

We use the volumetric soil moisture for $10-200 \mathrm{~cm}$ depth from the NCAR/NCEP reanalysis daily average surface flux data set (http://www.esrl.noaa.gov/psd/data/gridded/ data.ncep.reanalysis.surfaceflux.html) (Kalnay et al., 1996). The data is available at global scales at daily timesteps for the period 1948 to present on a Gaussian grid. We reproject the data onto the orthogonal GEOS-4 grid for model fitting.

\section{Leaf phenology model}

The central assumption of our model is that trees adjust their gains and losses of leaves in order to try to achieve, at any given time, an optimal LAI, which we refer to as the target LAI, $\mathrm{LAI}_{\text {targ }}$. The value of $\mathrm{LAI}_{\text {targ }}$ is determined as the minimum of a light-limited target, LAI $_{\text {targ }}^{\text {light }}$, and a water-limited target, $\mathrm{LAI}_{\mathrm{targ}}^{\mathrm{water}}$. We define LAI $\mathrm{I}_{\text {targ }}^{\text {light }}$ such that the bottom layer of leaves receives just enough light to return a positive carbon balance, i.e., receives light at the light compensation 
Table 1. Model parameters

\begin{tabular}{lll}
\hline Symbol & Units & Description \\
\hline$C_{\text {direct }}$ & $\mathrm{Wm}^{-2}$ & Light compensation point for direct PAR (Eq. 1, main paper) \\
$C_{\text {diffuse }}$ & $\mathrm{Wm}^{-2}$ & Light compensation point for diffuse PAR (Eq. 1, main paper) \\
$p$ & days & Length of time window for average PAR \\
gain & $\mathrm{m}_{\text {max }}^{2} \mathrm{~m}^{-2}$ & Maximum gain rate for new leaves \\
$a_{\text {crit }}$ & years & Age after which leaves start ageing \\
$\mu_{0}$ & years & Background decay constant \\
$\mu_{1}$ & years & Age-related decay constant \\
\hline
\end{tabular}

point $C$ as derived from Beer's law:

$\mathrm{LAI}_{\text {targ }}^{\text {light }}=-\frac{1}{\alpha} \ln \left(\frac{C}{I_{0}}\right)$,

where $I_{0}$ is the incoming PAR at the top of the canopy and $\alpha$ is the light attenuation coefficient applying to Beer's Law, which we have fixed to 0.5 (Appendix A1). To recognise the potentially important difference between direct and diffuse light we apply Eq. 1 separately for both direct and diffuse PAR, to determine their respective compensation points ( $C_{\text {direct }}$ and $C_{\text {diffuse }}$, and then keep the minimum of the two values. For both diffuse and direct PAR we assume that, in order to avoid sub-optimal responses to very short-term variation in light, trees calculate the target $\mathrm{LAI}_{\text {targ }}^{\text {light }}$ using an effective $I_{0}$, defined as the average over the previous $p$ days. We drive Eq. 1 with GEOS-4 reanalysis estimates of incoming PAR (Sect. 2.2). We define the water-limited target as $\mathrm{LAI}_{\text {targ }}^{\text {water }}=\beta_{1}+\beta_{2} W_{\mathrm{s}}$, where $W_{\mathrm{s}}$ is soil moisture (from the NCAR/NCEP Reanalysis, Sect. 2.3) and $\beta_{1}$ and $\beta_{2}$ are empirical coefficients (Appendix A2) We assume leaf demography (the gain and loss of leaves of different ages) is determined by the factor limiting $\mathrm{LAI}_{\mathrm{targ}}$. If the current $\mathrm{LAI}$ is below $\mathrm{LAI}_{\text {targ }}$ trees add new leaves of age $a=0$ at a maximum rate gain ${ }_{\text {max }}$ to reach $\mathrm{LAI}_{\text {targ }}$. If $\mathrm{LAI}_{\text {targ }}$ is water limited and the current $\mathrm{LAI}$ is above $\mathrm{LAI}_{\text {targ }}$, to avoid excessive water loss or overheating leaves, trees lose leaves, beginning with the oldest leaves, until they achieve $\mathrm{LAI}_{\text {targ }}$. When $\mathrm{LAI}_{\text {targ }}$ is light limited and LAI is above $\mathrm{LAI}_{\text {targ }}$, trees add no new leaves, but do not actively drop leaves. In all of the above cases, leaves are subject to continuous leaf loss according to a mortality rate $\mu$ due to leaf ageing that depends only on leaf age $a$. We define a minimum age, $a_{\text {crit }}$ (years), below which we only consider the background loss, e.g. herbivory, branch loss, so that the mortality is $\mu=\exp ^{-\mu_{0}}$. Leaves older than $a_{\text {crit }}$ are lost at a faster rate $\mu=\exp ^{-\mu_{1}}$ which is caused by leaf ageing. In order to calculate the age-dependent mortality we introduce the concept of leaf cohorts, defined as a group of leaves of the same age. For each cohort $\operatorname{LAI}(a, \mathbf{x}, t)$ we apply the mortality rate as:

$\operatorname{LAI}(a, \mathbf{x}, t)=\mu(a) \operatorname{LAI}(a-1, \mathbf{x}, t-1)$, with the mortality rate $\mu$ defined as above. The overall LAI at each time step, $\operatorname{LAI}(\mathbf{x}, t)$ is the sum of all leaf cohorts.

Overall the rate of change of LAI at each location $\mathbf{x}$ and time $t$ (Fig. 2) is:

$$
\begin{aligned}
\frac{d}{d t}(\operatorname{LAI}(\mathbf{x}, t))=P( & \left.I_{0}(\mathbf{x}, t), \operatorname{LAI}(\mathbf{x}, t-1)\right)- \\
& -L\left(\operatorname{LAI}(\mathbf{x}, t), W_{\mathrm{s}}(\mathbf{x}, t)\right),
\end{aligned}
$$

where $P\left(I_{0}(\mathbf{x}, t), \operatorname{LAI}(\mathbf{x}, t-1)\right)$ denotes production processes and $L\left(\operatorname{LAI}(\mathbf{x}, t) W_{\mathrm{s}}(\mathbf{x}, t)\right)$, refers to loss processes due to both the age-related mortality rate and active leaf dropping due to water stress. When integrated over time $t$, Eq. 3 provides, for each location $\mathbf{x}$ and time $t$, a predicted LAI (Appendix B1) given environmental drivers (direct and diffuse PAR, and available soil moisture), and given the value of 9 parameters specific to location x: $C_{\text {direct }}, C_{\text {diffuse }}, p$, gain max $_{\text {mat }}, a_{\text {crit }}, \mu_{0}, \mu_{1}, \beta_{1}, \beta_{2}$ (Table 1). Initial parameter estimates (not shown) estimated that $\mathrm{LAI}_{\text {targ }}^{\text {light }}<\mathrm{LAI}_{\text {targ }}^{\text {water }}$ for nearly all locations at nearly all times, such that the fit to data was not statistically improved by considering water limitation of leaf area so that we can set $\mathrm{LAI}_{\text {targ }}=\mathrm{LAI}_{\text {targ }}^{\text {light }}$ consequently we do not discuss soil moisture further.

We simultaneously fit the above parameters using a Bayesian approach (Appendix B) over our study region with a spatial resolution of $2^{\circ}$ (latitude) $\times 2.5^{\circ}$ (longitude) to collection 5 of the LAI data from the MODIS satellite instrument, which was spatially averaged to this resolution (Sect. 2.1).

\section{Results}

Fig. 3 shows that the model reproduces the spatial distribution of mean LAI (Pearson correlation coefficient $r^{2}=$ 0.9 ), capturing the high values (up to $4.8 \pm 0.1 \mathrm{~m}^{2} \mathrm{~m}^{-2}$ ) over the central and southern Amazon basin and lower values $\left(4.0 \pm 0.2 \mathrm{~m}^{2} \mathrm{~m}^{-2}\right)$ over the Eastern regions. More importantly, the model reproduces the broad spatial distribution of LAI amplitude, defined as the difference between the maximum and minimum monthly LAI, with a statistically significant correlation coefficient of $r^{2}=0.46$. This result supports 
Begin calculation

Calculate a temporary leaf age distribution (time $t$ ) from the previous distribution (time $t-\Delta t$ ):

(1) For all $a$, calculate $\mu\left(a, \theta_{x}\right)$

(2) For all $a \geq \Delta t$, set

$L A I_{\text {prod }}\left(a, x, t, \boldsymbol{\theta}_{x}\right)=\exp \left(-\mu L\left(a-\Delta t, \theta_{x}\right) \cdot \Delta t\right) \cdot L A I_{\text {prod }}\left(a-\Delta t, x, t-\Delta t, \boldsymbol{\theta}_{x}\right)$

(3) For all $a<\Delta t$ temporarily set $L A I_{\text {prod }}\left(a, x, t, \boldsymbol{\theta}_{x}\right)=0$

(4) Sum the above over all a to give a temporary $L A I_{\text {prod }}\left(x, t, \boldsymbol{\theta}_{x}\right)$

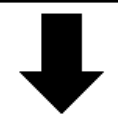

Calculate effective incoming radiation

(1) retrieve direct PAR for location $x$, for each of $p_{x}$ days running up to day $t$.

The mean of these values is $\hat{l}_{\text {diret }}\left(x, t, \boldsymbol{\theta}_{x}\right)$.

(2) retrieve diffuse PAR for location $x$, for each of $p_{x}$ days running up to day

$t$. The mean of these values is $\hat{I}_{\text {diftus }}\left(x, t, \boldsymbol{\theta}_{x}\right)$.

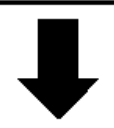
Calculate target LAI
(1) Calculate $L A I_{\text {tare diret }}\left(x, t, \boldsymbol{\theta}_{x}\right)$ given $\hat{l}_{\text {dirser }}\left(x, t, \boldsymbol{\theta}_{x}\right)$.
(2) Calculate $L A I_{\text {targ diftes }}\left(x, t, \boldsymbol{\theta}_{x}\right)$ given $\hat{I}_{\text {diftes }}\left(x, t, \boldsymbol{\theta}_{x}\right)$.
(3) The minimum of the above is $L A I_{\text {two }}\left(x, t, \boldsymbol{\theta}_{x}\right)$
(4) Is $L A I_{\text {prod }}\left(x, t, \boldsymbol{\theta}_{x}\right)<L A I_{\text {targ }}\left(x, t, \boldsymbol{\theta}_{x}\right)$ ?

\begin{tabular}{|c|c|c|}
\hline \multicolumn{3}{|l|}{ Notation } \\
\hline Symbol & Meaning & Units \\
\hline$L A I_{\text {prod }}\left(a, x, t, \theta_{x}\right)$ & $\begin{array}{l}\text { Predicted LAI summed over } \\
\text { leaves of age } a \text {, at location } x \text {, } \\
\text { at time } t\end{array}$ & $\begin{array}{l}m^{2} \pi^{-2} \text { (leaf area per unit } \\
\text { ground area) }\end{array}$ \\
\hline$\theta_{x}$ & $\begin{array}{l}\text { Vector of par ameters for } \\
\text { location } x\end{array}$ & Units depend on parameter \\
\hline$\mu\left(a, \theta_{x}\right)$ & $\begin{array}{l}\text { Background mort ality rate of } \\
\text { leaves of age } a\end{array}$ & day $y^{-1}$ \\
\hline PAR & $\begin{array}{l}\text { Photosynthetically active } \\
\text { radiation }\end{array}$ & $w m^{-2}$ \\
\hline$\hat{I}_{\text {dirot }}\left(x, t, \theta_{x}\right)$ & $\begin{array}{l}\text { Effective PAR used to } \\
\text { calcul ated target LAI, direct } \\
\text { only }\end{array}$ & $w m^{-2}$ \\
\hline$\hat{I}_{\text {diftess }}\left(x, t, \theta_{x}\right)$ & $\begin{array}{l}\text { Effective PAR uged to } \\
\text { calcul ated target LAI, direct } \\
\text { only }\end{array}$ & $w m^{-2}$ \\
\hline$L A I_{\text {targ,difert }}\left(x, t, \theta_{x}\right)$ & $\begin{array}{l}\text { Target LAI, con sidering only } \\
\text { direct PAR }\end{array}$ & $m^{2} m^{-2}$ \\
\hline$L A I_{\text {ing,diffes }}\left(x, t, \theta_{x}\right)$ & $\begin{array}{l}\text { Target LAI, con sidering only } \\
\text { diffuse PAR }\end{array}$ & $m^{2} \pi^{-2}$ \\
\hline$L A I_{\text {tars }}\left(x, t, \theta_{x}\right)$ & $\begin{array}{l}\text { Target LAI, considering both } \\
\text { direct and diffuse PAR }\end{array}$ & $m^{2} \pi^{-2}$ \\
\hline $\operatorname{gain}_{\operatorname{smx}}$ & $\begin{array}{l}\text { Parameter: maximum } \\
\text { possible gain rates of leaves } \\
\text { at location } x\end{array}$ & $m^{2} m^{-2}$ day $y^{-1}$ \\
\hline
\end{tabular}

yes

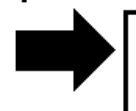

Gain leaves

Is $L A I_{\text {targ }}\left(x, t, \theta_{x}\right)-L A I_{\text {prod }}\left(x, t, \theta_{x}\right)<$ gain $_{\max }$ ?

no yes

Gain sufficient leaves to achieve target LAI

Set $L A I_{\text {prod }}\left(0, x, t, \theta_{x}\right)=L A I_{\text {targ }}\left(x, t, \theta_{x}\right)-L A I_{\text {prod }}\left(x, t, \theta_{x}\right)$

Gain leaves at maximum rate

Set $L A I_{\text {prod }}\left(0, x, t, \theta_{x}\right)=$ gain $_{\text {raxx }}$

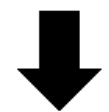

Calculation complete for timet

For time $t+\Delta t$, return to step 1 above

Fig. 2. How to calculate the predicted leaf age distribution and predicted total LAI for a model driven only by light. Note that the calculation begins with the leaf age distribution from a previous time $t-\delta t$ at the same location, which is updated to account for background leaf mortality, and the addition of new (age $=0$ ) leaves as driven by the LAI target, producing a predicted leaf age distribution for time $t$. 
a
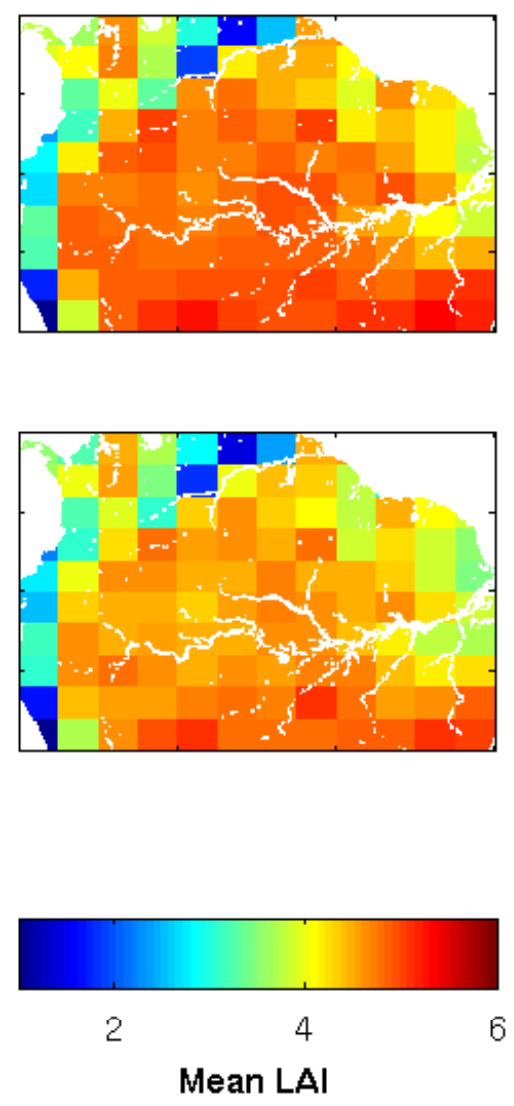

b
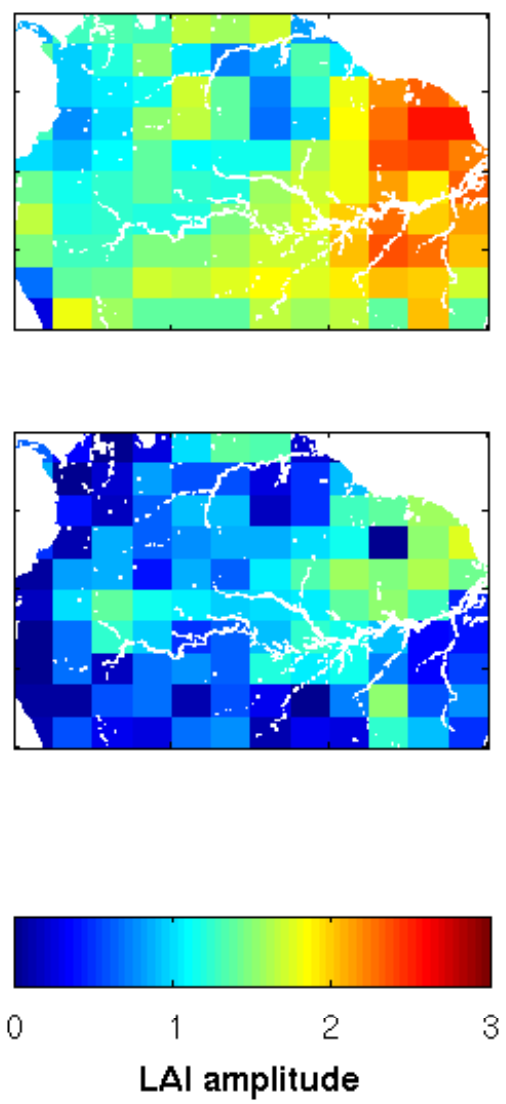

c
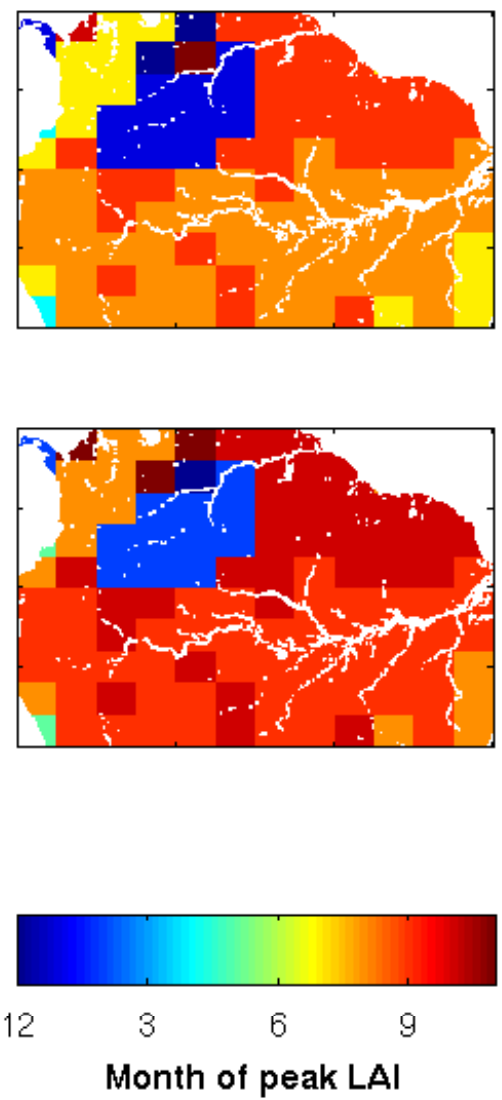

Fig. 3. MODIS (top) and model (bottom) leaf area index (LAI) over the Amazon $\left(10^{\circ} \mathrm{N}-10^{\circ} \mathrm{S}, 80^{\circ} \mathrm{W}-50^{\circ} \mathrm{W}\right), 2001-2005$ averaged over a $1 \times 1 \mathrm{~km}$ grid. (a) mean LAI $\left(\mathrm{m}^{2} \mathrm{~m}^{-2}\right)$, (b) mean annual amplitude of LAI $\left(\mathrm{m}^{2} \mathrm{~m}^{-2}\right)$, and (c) mean timing of peak LAI (day of year).

our model structure because, unlike the mean LAI, the LAI amplitude is highly constrained by model assumptions; the maximum LAI amplitude is determined by the amplitude of incoming PAR.

Figure 4 shows that the model generally has a negative bias with respect to amplitude, which we attribute at least in part to measurement noise, with mean MODIS (model) LAI amplitude of $1.5 \pm 0.4(0.7 \pm 0.4) \mathrm{m}^{2} \mathrm{~m}^{-2}$, but the MODIS value falls within the confidence intervals of the model (Fig. 5). Similarly, the model reproduces the seasonal timing of LAI variation (Fig. 4), which is also highly constrained by the model structure, as the greatest target LAI occurs at the time of peak incoming PAR. We find that our model generally describes between $20-80 \%$ (median of $31 \%$ ) of the observed temporal variability of LAI at any one $2^{\circ} \times 2.5^{\circ}$ grid cell.

Fig. 6 shows posterior model parameters, which provide further insight into the underlying processes that determine observed variations in LAI. The spatial variations of the parameters are a reflection of not only the seasonality but also of species composition, soil type or nutrient availability. The two compensation points, $C_{\text {direct }}$ and $C_{\text {diffuse }}$, can be inter- preted as a measure of the shade adaptation in trees, with a lower compensation point indicating leaves that are adapted for lower light conditions. We estimate that $C_{\text {direct }}$ is lower in the south of the Amazon, with values of 1.5 compared to $5 \mathrm{Wm}^{-2}$ elsewhere. In contrast, $C_{\text {diffuse, }}$, which effectively limits the overall compensation point during the dry season resulting in a lower LAI amplitude, is more homogeneous across the basin with mean values of $0.23 \mathrm{Wm}^{-2}$. Our values for the compensation points are broadly consistent with ground-based measurements (Riddoch et al., 1991), providing further support for our methodology.

The delay $p$ represents the time required for the vegetation to respond to changes in PAR. We find that $p$ is generally 14 days for most of the basin. The exception is over the northwestern region, where $p>1$ month, suggesting that vegetation over this region is slower to respond to changes in PAR. The maximum gain of LAI is typically around $1 \mathrm{~m}^{2} \mathrm{~m}^{-2} \mathrm{month}^{-1}$, with the highest values (up to $2.2 \mathrm{~m}^{2} \mathrm{~m}^{-2} \mathrm{month}^{-1}$ ) over the eastern, drier regions corresponding to an area with a higher LAI amplitude and a more pronounced seasonal cycle. 
a

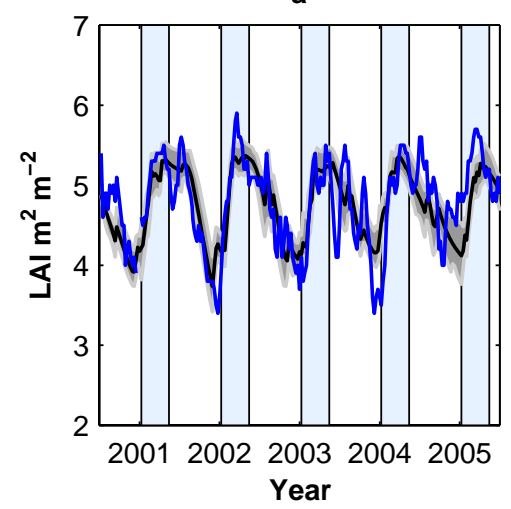

b

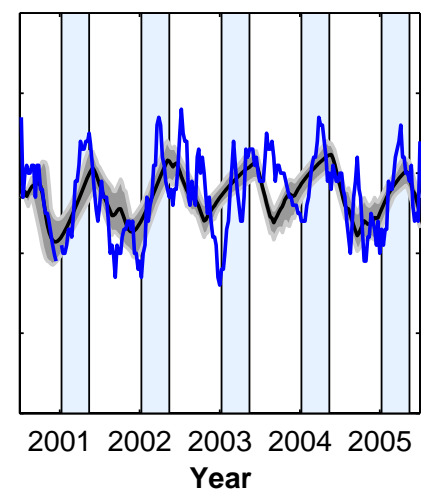

c

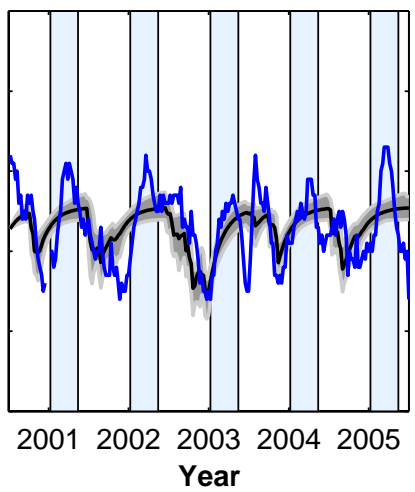

Fig. 4. LAI time series in (a) the eastern Amazon $\left(8^{\circ} \mathrm{N} 62.5^{\circ} \mathrm{W}\right)$, (b) the semi-deciduous Amazon $\left(0^{\circ} \mathrm{N} 72.5^{\circ} \mathrm{W}\right)$, and $(\mathbf{c})$ the evergreen central Amazon basin $\left(4^{\circ} \mathrm{N} 67.5^{\circ} \mathrm{W}\right)$, as predicted by the model (black line) and MODIS LAI data (blue line). Gray shaded area represents $95 \%$ confidence intervals. Blue bands represent aproximate dry seasons.

a
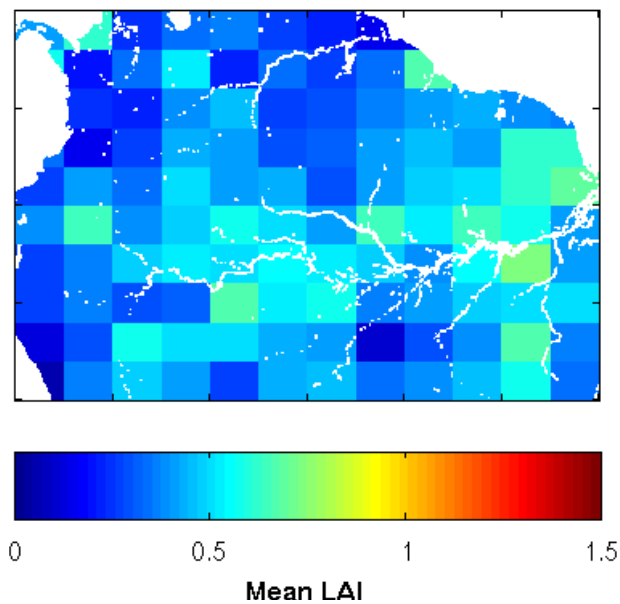

b
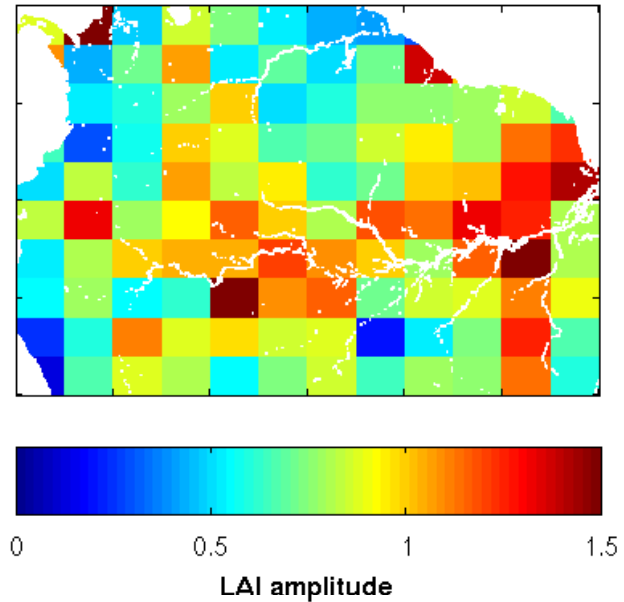

Fig. 5. Model uncertainty for mean LAI and annual amplitude (the difference between the maximum and minimum monthly LAI). We used samples drawn from the posterior distribution to calculate model LAI values and then obtain posterior means and confidence intervals. Here, the uncertainty is represented as the difference between the upper and lower bounds of the $95 \%$ conidence intervals using parameter posterior distributions.

To help interpret our estimated leaf loss parameters, determined by the amplitude of the observed LAI seasonal cycle, we calculate a leaf lifespan $\tau_{95}$ as the time at which $95 \%$ of the leaves from a cohort have dropped, based on the exponential decay rates $\mu_{0}$ and $\mu_{1}$ (Eq. 2):

$\tau_{95}=-\frac{\ln 0.05}{\mu_{1}}-\frac{\mu_{0}}{\mu_{1}} a_{\text {crit }}+a_{\text {crit }}$,

with variables as defined in Table 1. Figure 6 shows that $\tau_{95}$ is longest in the middle of the Amazon basin, with values of around $2.1 \pm 0.2$ years, and lower in the Southern and Eastern regions ( $1.5 \pm 0.7$ years), where the vegetation has a larger deciduous component.

These lifetimes are consistent with sparse ground-based studies over the same region, which report values between 2 months and 6.4 years (Reich et al., 2004) and in other tropical forests (up to 26 months (Sharpe, 1997; Osada et al., 2001)).

To obtain an estimate of parameter uncertainty, we use the posterior distribution resulting from the fitting algorithm to calculate 95\% confidence intervals (Fig. 7). Most parameters are well constrained, with confidence intervals of 0.1 $( \pm 0.07)$ of the posterior mean for most parameters. The exceptions are two of the leaf mortality parameters (Fig. $7 \mathrm{f}$ and $\mathrm{g})$, with confidence intervals of $0.8( \pm 0.2)$ for the base mortality rates, $\mu_{0}$ and $0.5( \pm 0.1)$ for the age related rate, $\mu_{1}$. This can indicate a trade-off between the two parameters as they both contribute to determining the overall leaf lifespan. Also, the diffuse compensation point $C_{\text {diffuse }}$ (Fig. 7b) is less well constrained in the north-eastern regions. 
a

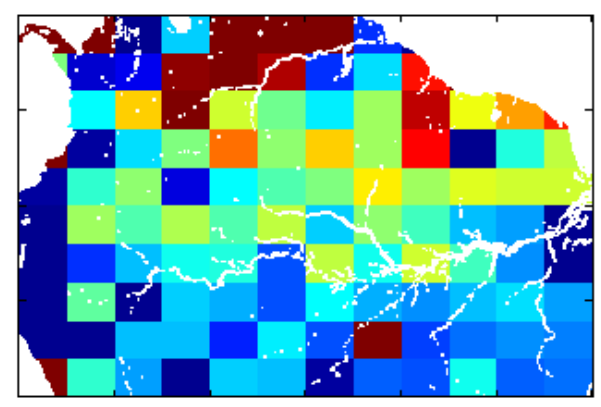

c

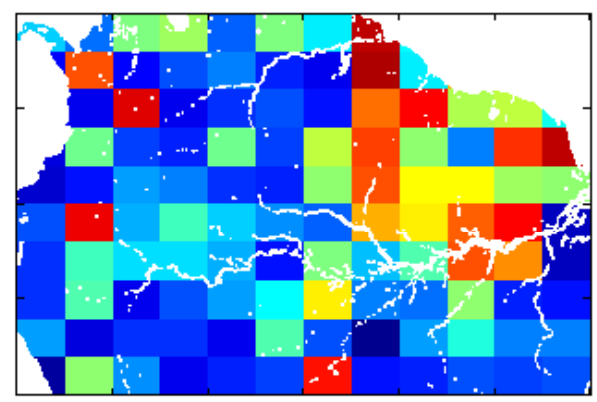

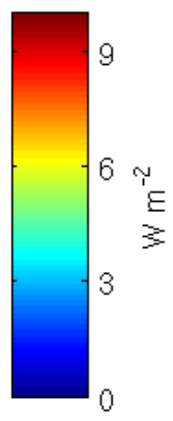

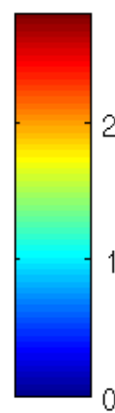

b

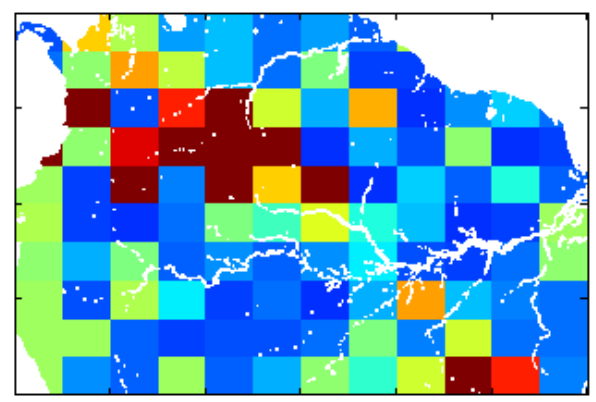

d

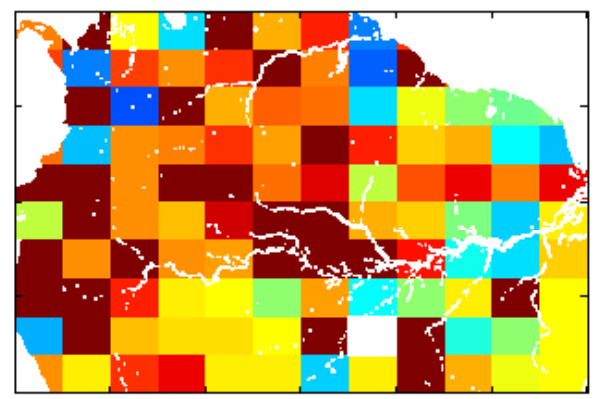

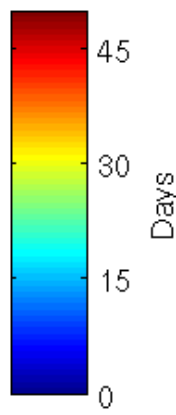

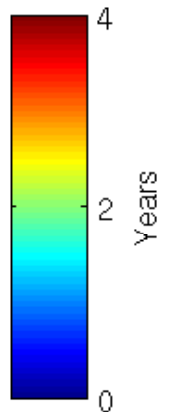

Fig. 6. Mean posterior parameters that describe leaf gain and loss: (a) direct PAR compensation point, $C_{\text {direct }}\left(\mathrm{W} \mathrm{m}^{-2}\right)$; (b) delay in vegetation response to changes in PAR, $p$ (days); (c) maximum number of leaves that can be added over a month, gain $\mathrm{max}\left(\mathrm{m}^{2} \mathrm{~m}^{-2} \mathrm{month}^{-1}\right)$; and (d) mean cohort leaf lifetime $\tau_{95}$ defined as the time at which $95 \%$ of the leaves from a cohort have dropped (years).

Our model also allows us to estimate the leaf age distribution at any point over the basin, something that would be extremely difficult to do using traditional means. Fig. 8 shows that leaves in regions with a high leaf turnover rate are generally younger than one year, with a high proportion of very young leaves (less than 6 months) with an approximately exponential leaf age distribution which shows pronounced seasonality between wet and dry seasons. In contrast, over the evergreen areas of the central Amazon basin we estimate a higher proportion of leaves older than 1 year and a leaf age distribution with a less pronounced seasonality. In the more deciduous regions in the southern basin, we find distinct leaf cohorts originating from past growing seasons.

To provide an example of the potential impact of our new estimates of leaf age distribution on large-scale calculations of biogeochemistry, we incorporated this information into a simple model of carbon assimilation. We present three scenarios: (1) using a constant LAI and constant leaf age distribution throughout the year, (2) using the predicted LAI with a constant leaf age distribution and (3) using the predicted LAI and leaf age distribution. Fig. 9 shows that the seasonality of the carbon flux is driven mainly by the incoming PAR and not by changes in LAI. When we include the predicted LAI, the overall photosynthesis is higher by only approximately $1 \mu \mathrm{mol} \mathrm{m}{ }^{-2} \mathrm{~s}^{-1}$ during the dry season. However, if we include a leaf age adjusting factor (Appendix C), the assimilation rate is lower by an average of $1.5 \mu \mathrm{mol} \mathrm{m}^{-2} \mathrm{~s}^{-1}$ through- out the year. The largest difference $\left(3.37 \mu \mathrm{mol} \mathrm{m}^{-2} \mathrm{~s}^{-1}\right)$ occurs in June, when the new leaves start appearing in response to increased sunlight. The assimilation also peaks later than when using a constant LAI, as new leaves reach peak photosynthetic rates only after a certain period of time. While some ground studies report a decrease in assimilation rate during dry periods (Malhi et al., 1998; Miranda et al., 2005) and during severe drought periods (Phillips et al., 2009), the lower assimilation rate at the start of the dry season has been observed in ground studies (Hutyra et al., 2007; Goulden et al., 2004; Graham et al., 2003; Bonal et al., 2008; da Rocha et al., 2004) but previous models were unable to predict this pattern. The hypothesis advanced by one of these studies (Hutyra et al., 2007) was that the emergence of new leaves at the start of the dry season would create this pattern, which is quantitatively supported by the leaf demography predicted by our model.

\section{Concluding remarks}

We present a simple phenology model for the Amazon basin, which we fitted to 5 years of MODIS LAI data. We showed that our model reproduced the observed increase in LAI during the dry season as a response to an increase in direct solar radiation. Our model parameters provided further information about the vegetation in the Amazon basin. The 
a

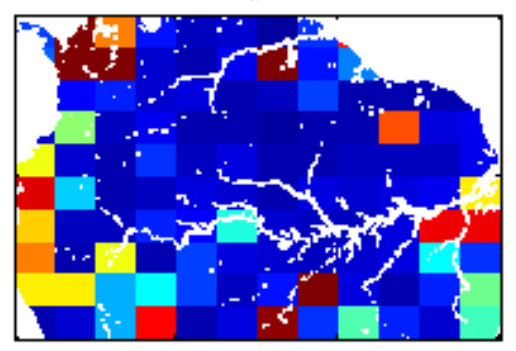

$\mathrm{c}$

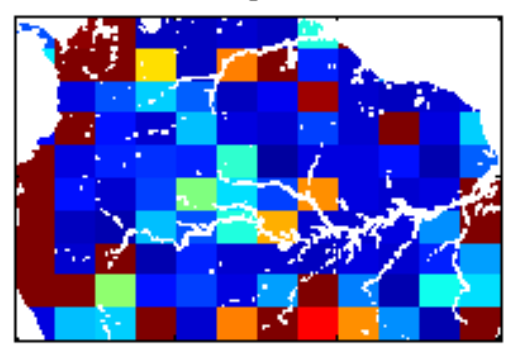

e

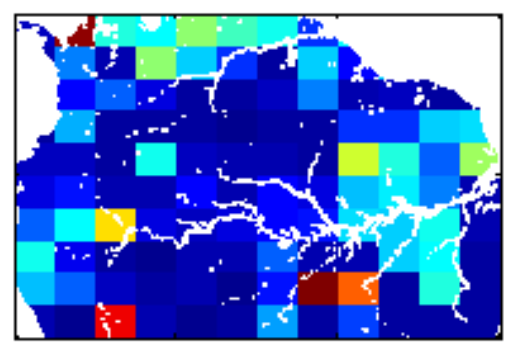

b

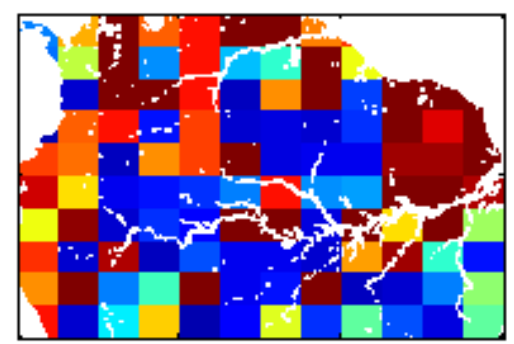

d

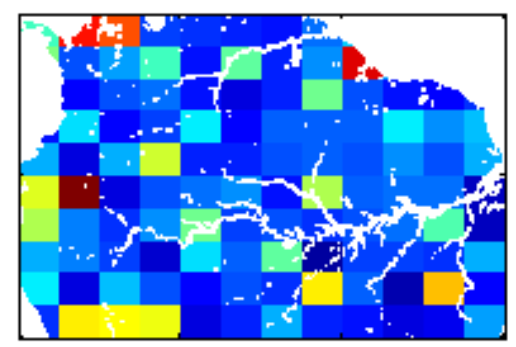

f

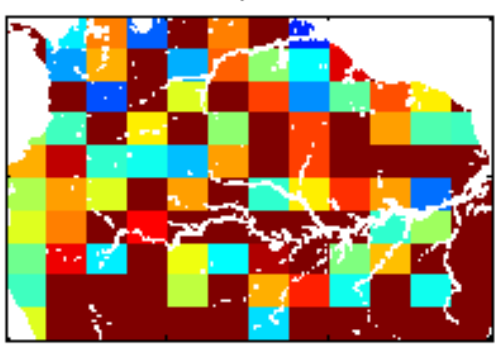

9

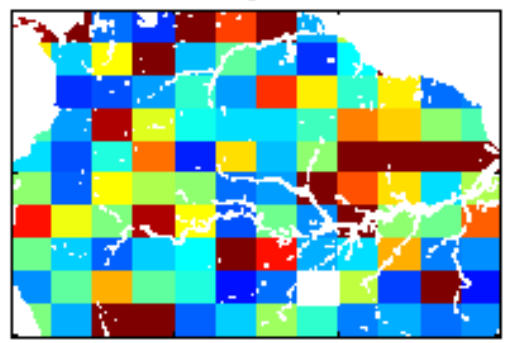

0

$$
0.2
$$

0.4

0.6

0.8

1

Fig. 7. Parameter uncertainty derived from the posterior distribution, expressed as $95 \%$ confidence intervals relative to posterior means for (a) direct PAR compensation point, $C_{\text {direct }}$; (b) diffuse PAR compensation point, $C_{\text {diffuse; }}$; (c) delay in vegetation response to changes in PAR, $p$; (d) maximum number of leaves that can be added over a month, gain ${ }_{\max }$; (e) age after which age related decay starts, age crit $_{\text {; }}$; (f) background decay constant, $\mu_{0}$ and (g) age-related decay constant, $\mu_{1}$. 
a

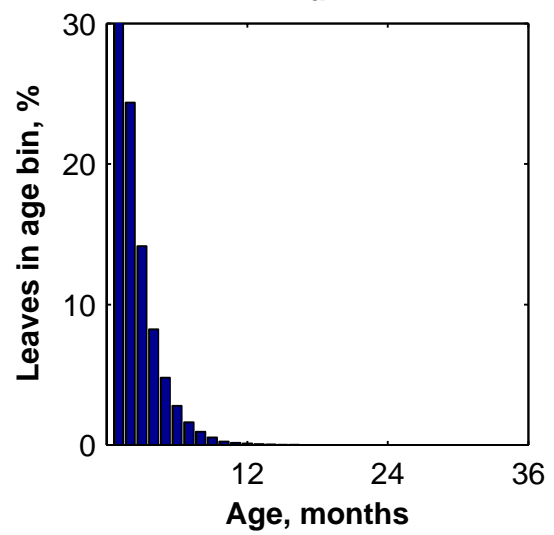

b

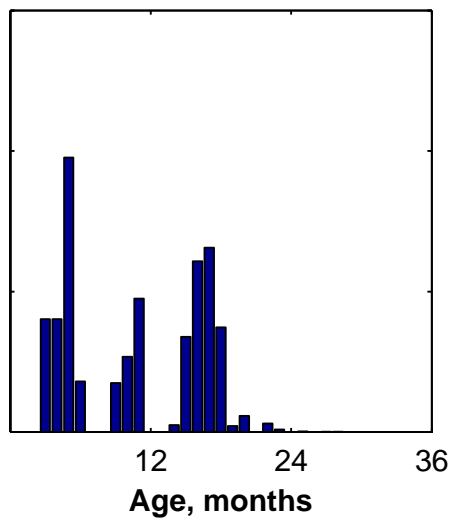

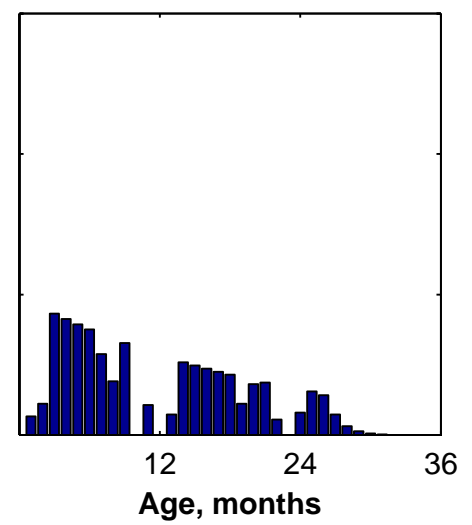

Fig. 8. Estimated frequency distribution of leaf ages (months) over (a) the eastern Amazon, where leaves are typically short-lived, (b) over the semi-deciduous Amazon, and (c) over the evergreen central Amazon basin. All locations are the same as for Fig. 4.

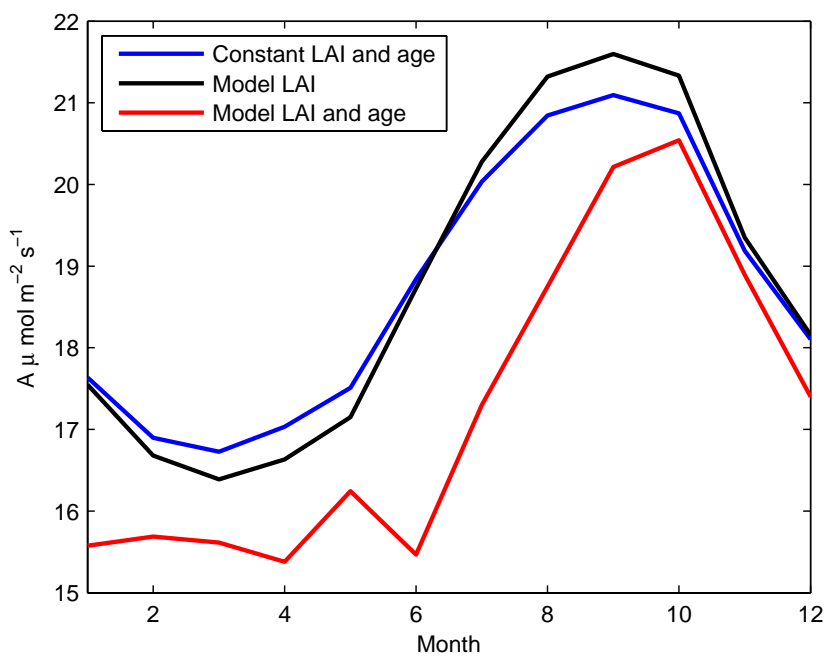

Fig. 9. Gross carbon assimilation calculated using a simple carbon model for a constant LAI, model LAI and model LAI including the temporal variations in leaf age. The values presented are monthly means over a 5 year period at one location $\left(8^{\circ} \mathrm{N} 55^{\circ} \mathrm{W}\right)$. All values are $\mu \mathrm{mol} \mathrm{m} \mathrm{m}^{-1} \mathrm{~s}^{-1}$.

model also provided leaf demography estimates, which can be used to improve predictions of the seasonal carbon cycle, which we demonstrated in principle using a simple carbon model. We showed that using our predicted leaf demography explains observed decrease in carbon assimilation at the start of the dry season. Carbon fixation is only one of many examples of leaf-age-dependent processes of which our current understanding is hampered by incomplete knowledge of leaf demography. Recent work has shown that including a better description of leaf phenology in Earth system models can significantly revise estimates of land surface warming (Bounoua et al., 2010). The demographic model presented here can be used to predict responses of Amazon leaf demography to future changes in climate and could be extended to include other tropical regions where leaf phenology is driven partially or wholly by soil moisture. We therefore anticipate that the insights afforded by our analysis will have far-reaching implications for improving current understanding of the natural carbon cycle in the Amazon and elsewhere.

\section{Appendix A}

\section{Model structure}

\section{A1 Attenuation Coefficient}

To quantify the attenuation of photosynthetic active radiation (PAR) as it passes through a forest canopy, we used Beer's law:

$I=I_{0} e^{-\alpha L}$,

where $I_{0}$ is the incoming PAR $\left(\mathrm{Wm}^{-2}\right)$ at the top of the canopy, $I$ is the light level at layer $L$ inside the canopy and $\alpha$ is the light attenuation coefficient. We assume a vertically homogeneous canopy with no leaf clumping. The light attenuation coefficient is a function of the solar inclination angle, $\phi$. For a random distribution of leaf angles this is equal to $\alpha=\frac{0.5}{\sin \phi}$. We use a homogeneous canopy with no leaf clumping and a random leaf angle distribution as these assumptions are valid for canopies at a large scale. Because we are using daily time scales, we can, for simplicity, calculate the attenuation coefficient at its maximum value for a solar angle equal to $90^{\circ}$. For non-directional (diffuse) radiation the attenuation coefficient can be calculated as the median value over all possible radiation angles. The median is used here rather than the mean to avoid the excessive influence of very small or very large angles. 
Table A1. Comparison of leaf litterfall as predicted by the model and ground-based measurements across the Amazon basin.

\begin{tabular}{|c|c|c|c|}
\hline Location & Measured litterfall & $\begin{array}{l}\text { Predicted } \\
\text { leaf loss }\end{array}$ & Reference \\
\hline $2^{\circ} 51^{\prime} \mathrm{S} 54^{\circ} 58^{\prime} \mathrm{W}$ & $0.25-0.81(8.16)$ & $0.47-0.62$ & $\begin{array}{l}\text { Malhado et al. (2009), } \\
\text { Doughty and Goulden (2008) }\end{array}$ \\
\hline $0^{\circ} 25^{\prime}-1^{\circ} 30^{\prime} \mathrm{S}, 72^{\circ} 30^{\prime}-70^{\circ} 40^{\prime} \mathrm{W}$ & $0.24-0.55$ & $0.03-0.11$ & Lips and Duivenvoorden (1996) \\
\hline $11^{\circ} 24^{\prime} \mathrm{S} 55^{\circ} 19^{\prime} \mathrm{W}$ & $0.11-1.42$ & $0.002-0.14$ & Sanches et al. (2008) \\
\hline $4^{\circ} 45^{\prime}-05^{\circ} 30^{\prime} \mathrm{N} 60^{\circ} 30^{\prime}-61^{\circ} 22^{\prime} \mathrm{W}$ & $0.17-0.72$ & $0.52-0.56$ & Dezzeo and Chacon (2006) \\
\hline
\end{tabular}

\section{A2 Soil Water Target}

Soil water is widely recognised as a primary constraint in LAI, and the seasonality of LAI, in many different vegetation types around the world. For an individual tree, a greater leaf area implies a higher stomatal conductance and hence a greater potential rate of evapotranspiration. If this potential rate cannot readily be met with available soil moisture, the tree can either keep stomata open, risking excessive water loss, cavitation and hence drought death; or close the stomata, which greatly reduces water loss, but also shuts down photosynthesis and risks leaves overheating, causing permanent damage to the leaves; or the tree can reduce its total leaf area, thus allowing for individual leaves to maintain evapotranspiration and photosynthesis without excessive water use overall (McDowell et al., 2008). The first two options are short term responses to unpredictable drought, whereas losing leaves is the more sensible response to the seasonal variation in soil moisture that drives leaf phenology. Therefore, we assume that where the current LAI exceeds the waterlimited LAI LAI targ , trees would drop leaves in order to reach LAI $_{\text {targ }}^{\text {water }}$, starting with the oldest leaves, to produce a leaf demography that is sustainable in the long term (see main text).

Based on these assumptions, we specify a relationship between soil moisture and $\mathrm{LAI}_{\mathrm{targ}}^{\mathrm{water}}$ as:

$\mathrm{LAI}_{\text {targ }}^{\mathrm{water}}=\beta_{1}+\beta_{2} W_{\mathrm{s}}$

where $W_{\mathrm{s}}$ is the percentage soil moisture, and $\beta_{1}$ and $\beta_{2}$ are empirical coefficients. If the current LAI is above this target, trees will drop leaves until they reach $\mathrm{LAI}_{\mathrm{targ}}^{\mathrm{water}}$.

We assume trees actively drop leaves when LAI exceeds LAI $_{\text {targ }}^{\text {water }}$, but do not do so when LAI exceeds LAI targ $_{\text {tight }}$. Where LAI exceeds LAI $_{\text {targ }}^{\text {ligh }}$, the leaves receiving the least light will be below their compensation point and so be a net sink, rather than source, of carbon. However, the magnitude of this sink will be relatively small, when compared with the magnitude of the source from the leaves receiving more light. Also, trees can store substantial amounts of labile carbon, which can be used to offset short term deficits in carbon fixation. Therefore, where LAI exceeds LAI light likely to be a cause of whole plant stress or death. In contrast, as outlined above, where LAI exceeds $\mathrm{LAI}_{\text {targ }}^{\mathrm{water}}$, the lack of water affects the entire tree, and so could cause damage to all leaves, or to the whole plant through cavitation. In addition, very few trees store an amount of water that is significant in comparison to daily water use. Therefore, when LAI exceeds $\mathrm{LAI}_{\text {targ }}^{\mathrm{water}}$, the excess leaves are an immediate source of danger to the whole tree.

We fit the model using the method as described in Sect. B below, using NCEP/NCAR reanalysis derived soil moisture data (Kalnay et al., 1996). The values obtained for the $\beta_{1}$ and $\beta_{2}$ parameters result in a water limited target $\mathrm{LAI}_{\mathrm{targ}}^{\mathrm{water}}$ that is higher than the light limited target LAI $\mathrm{Atarg}_{\text {tight }}$ at all locations throughout the year, This implies that vegetation is never water limited. As a result we set $\mathrm{LAI}_{\text {targ }}=\mathrm{LAI}_{\text {targ }}^{\mathrm{water}}$, which results in the model structure described in Fig. 2.

\section{Appendix B}

\section{Parameter estimation}

The model has 7 free parameters (Table 1), which we fit independently for each location, resulting in 840 parameters.

Our aim was to estimate model parameters for location $\mathbf{x}$, which we denote as the vector $\theta_{\mathbf{x}}$, given the MODIS data for location $\mathbf{x}$, which we denote $Z_{\mathbf{x}}$. To do this we used a Bayesian approach, seeking to estimate the posterior probability distribution of $\theta_{\mathbf{x}}$, given $Z_{\mathbf{x}}$, which we denote $p\left(\theta_{\mathbf{x}} \mid Z_{\mathbf{x}}\right)$. The posterior $p\left(\theta_{\mathbf{x}} \mid Z_{\mathbf{x}}\right)$ is proportional to the product of the likelihood $L\left(Z_{\mathbf{x}} \mid \theta_{\mathbf{x}}\right)$, and the prior $p\left(\theta_{\mathbf{x}}\right)$ such that $p\left(\theta_{\mathbf{x}} \mid Z_{\mathbf{x}}\right) \propto L\left(Z_{\mathbf{x}} \mid \theta_{\mathbf{x}}\right) p\left(\theta_{\mathbf{x}}\right)$. Often, $p\left(\theta_{\mathbf{x}} \mid Z_{\mathbf{x}}\right)$ covers too large a region of parameter space to be evaluated completely. In this case we instead use sampling methods, which provide a set of random samples of $\theta_{\mathbf{x}}$ drawn from $p\left(\theta_{\mathbf{x}} \mid Z_{\mathbf{x}}\right)$. We used a Metropolis-Hastings Markov Chain Monte Carlo (MCMC) sampling routine (Gilks, 1996.).

We define the likelihood as

$$
l\left(Z_{\mathbf{x}} \mid \theta_{\mathbf{x}}\right)=\sum_{t(\mathbf{x})} \ln \left[n\left(\operatorname{LAI}_{\mathrm{obs}}(\mathbf{x}, t), \mathrm{LAI}_{\mathrm{pred}}\left(\mathbf{x}, t, \theta_{\mathbf{x}}\right), \sigma_{\mathbf{x}}\right)\right]
$$

where $l\left(Z_{\mathbf{x}} \mid \theta_{\mathbf{x}}\right)$ is the log-likelihood; $\operatorname{LAI}_{\text {pred }}\left(\mathbf{x}, t, \theta_{\mathbf{x}}\right)$ is the predicted LAI at location $\mathbf{x}$ at time $t$ (this depends on the model parameters $\left.\theta_{\mathbf{x}}\right)$; $\mathrm{LAI}_{\mathrm{obs}}(\mathbf{x}, t)$ is the observed MODIS LAI at location $\mathbf{x}$ at time $t$; and $n\left(\mathrm{LAI}_{\mathrm{obs}}(\mathbf{x}, t)\right.$, 
$\left.\operatorname{LAI}_{\text {pred }}\left(\mathbf{x}, t, \theta_{\mathbf{x}}\right), \sigma_{\mathbf{x}}\right)$ denotes the probability density for observing $\mathrm{LAI}_{\mathrm{obs}}(\mathbf{x}, t)$ given a normal distribution with mean $\operatorname{LAI}_{\text {pred }}\left(\mathbf{x}, t, \theta_{\mathbf{x}}\right)$ and standard deviation $\sigma_{\mathbf{x}}$ where $\sigma_{\mathbf{x}}$ is a parameter that specifies the magnitude of unexplained variation in LAI. Eq. B1 represents a loop over all times $t$ for which observed LAI were available for location $\mathbf{x}$ (this set of times is denoted $t(\mathbf{x})$ in Eq. B1).

We initially used non-informative, uniform priors for all parameters. We assumed that, a priori, all parameter combinations were equally likely. However, we found that, with non-informative priors on all parameters, we could not properly constrain all parameters for all locations. Therefore, we assigned an informative prior on one of the parameters affecting the rate of gain and loss of leaves. We did this for one parameter only to keep the overall influence of priors to a minimum. We base our prior on an extensive study (Reich et al., 2004) of leaf lifespan (time after which all leaves are dead) in the northern Amazon. To define the prior we use the mean ( 2.35 years) and standard deviation ( 0.18 years) of these measurements. In our model, we define leaf lifespan $\tau_{95, \mathbf{x}}$ as the leaf age at which only $5 \%$ of leaves remain alive. This is a function of three model parameters: $\mu_{0, \mathbf{x}}, \mu_{1, \mathbf{x}}$ and $a_{\text {crit, } \mathbf{x}}$. Using this prior, the posterior in the MCMC sampling becomes:

$\ln \left(p\left(\theta_{\mathbf{x}} \mid Z_{\mathbf{x}}\right)\right)=l\left(Z_{\mathbf{x}} \mid \theta_{\mathbf{x}}\right)+\ln \left(n\left(\tau_{95, \mathbf{x}}, \hat{\tau}, \sigma_{\tau}\right)\right)$,

where $n\left(\tau_{95, \mathbf{x}}, \hat{\tau}, \sigma_{\tau}\right)$ is the probability density for $\theta_{95, \mathbf{x}}$ assuming that it is drawn from a normal distribution with mean $\hat{\tau}$ and standard deviation $\sigma_{\tau}$. This measure is only proportional to the posterior because it does not take into account an integration constant. However, when using MCMC sampling this is unimportant because the constant cancels out when calculating the probability for acceptance and rejection. With this simple leaf lifespan constraint in place, we found that all parameters converged for all locations and that leaf lifespan varies substantially across the region, showing that the parameter estimates were not overly influenced by the prior (otherwise all leaf lifespans would have converged on $\hat{\tau}$ ). Also, parameters not directly affecting $\tau_{95, \mathbf{x}}$ were estimated to have reasonable values, implying that the model structure, MODIS data, the prior on leaf lifespan, and previous knowledge on other parameters, were all consistent with each other.

We used Metropolis-Hastings MCMC sampling (hereafter MH-MCMC) to provide a set of 600 random samples from $p\left(\theta_{\mathbf{x}} \mid Z_{\mathbf{x}}\right)$. MH-MCMC is a widely recognised and simple, albeit computational heavy, method to provide samples from the posterior parameter distribution. MH-MCMC samples this distribution simply by proposing new parameter sets and accepting or rejecting these on the basis of their posteriors, according to a standard Metropolis criterion. Given a sufficient number of steps, the random walk reaches a quasiequilibrium, after which the average properties of the walk (e.g. the mean and standard deviation as measured against any one parameter) no longer change. After this quasiequilibrium has been reached, the current position of the algorithm at any one time constitutes a random sample from the posterior (Gelman, 2004). However, there is a great deal of freedom in exactly how to carry out MH-MCMC for a particular case, especially in how new parameter sets are proposed. For our analysis we used "Filzbach" ${ }^{1}$, a previously tested and robust algorithm.

We allowed 60000 iterations for the burn-in (the period to quasi-equilibrium), then sampled every 100 iterations from a further 60000 total iterations, thus providing our 600 samples from $p\left(\theta_{\mathbf{x}} \mid Z_{\mathbf{x}}\right)$. From these samples we calculated, for each parameter, the posterior mean, and 95 confidence intervals. All values reported in the paper are posterior means. We have used parameter sets drawn from this distribution to obtain LAI values (Fig. 2) and then calculate average LAI values and upper and lower $95 \%$ confidence bounds for all values.

\section{B1 Generating predicted LAI values}

In order to both parameterize, and run simulations of, our model, it was necessary to generate predicted LAI values for each location $\mathbf{x}$ and time $t$, (e.g. see the likelihood defined above). Importantly, as a demographic model, our model as defined in the main text produces rates of change of the LAI held within different leaf age classes. Therefore, to produce $\operatorname{LAI}\left(\mathbf{x}, t, \theta_{\mathbf{x}}\right)$ it is necessary to first, set an initial leaf age distribution, and second, simulate the model forward in time from this initial state, until we reach time $t$. The schematic for this is given in Fig. 2. To make our predictions for a given parameter set $\theta_{\mathbf{x}}$, we set the initial leaf age distribution as $\operatorname{LAI}\left(a, \mathbf{x}, t, \theta_{\mathbf{x}}\right)=0$ for all $a$ (corresponding to no leaves) then simulated the year 200010 times over, each time beginning the simulated year, using as the initial state the leaf age distribution from the end of the previous simulated year. This acted to spin up the model to produce a reasonable initial leaf age distribution consistent with current parameters. After the spin-up, we then simulated the model forward in time in steps of 8 days, keeping note of $\operatorname{LAI}\left(\mathbf{x}, t, \theta_{\mathbf{x}}\right)$ for all $t$ where we had observations of LAI with which to compare the predictions. Note that, although for the parameter estimation we only used the total $\operatorname{LAI}, \operatorname{LAI}\left(x, t, \theta_{\mathbf{x}}\right)$, the model can only be simulated by keeping track of the LAI within each age class, $\operatorname{LAI}\left(a, \mathbf{x}, t, \theta_{\mathbf{x}}\right)$. Thus predicted leaf age distributions emerge as a natural outcome of applying our model.

\footnotetext{
${ }^{1}$ Filzbach, a software library for carrying out MetropolisHastings Markov chain Monte Carlo parameter estimation in C++ or C\#. Filzbach is under development in the Computational Science lab at Microsoft Research Cambridge and is available for download, complete with a suite of example uses, via http://research.microsoft. com/en-us/groups/ecology/ecotechandtools.aspx
} 


\section{Appendix C}

\section{Carbon Assimilation Model}

To illustrate the impact that our model results have on the carbon cycle in the Amazon, we use a simple canopy model to describe leaf photosynthesis rates. We assume that the only limitation to photosynthesis is light availability, so that carbon assimilation rates are a linear function of incoming PAR:

$A(I)= \begin{cases}\phi I-q, I<I_{\max } \\ A_{\max }, I>I_{\max }\end{cases}$

where $A_{\max }$ is the maximum assimilation rate that occurs after photosynthesis reaches saturation with light for PAR levels above $I_{\max }$. We use literature values (Kubiske and Pregitzer, 1996; Riddoch et al., 1991; Langenheim et al., 1984; Miranda et al., 2005; Hutyra et al., 2007; Kitajima et al., 1997) to obtain an $A_{\max }$ of $6.12 \mu \mathrm{mol} \mathrm{m}^{-2} \mathrm{~s}^{-1}$ and $I_{\max }$ equal to $150 \mu \mathrm{mol} \mathrm{m}^{-2} \mathrm{~s}^{-1}$ (Hutyra et al., 2007). The values cited above have been measured for various locations, species and light environments which we have averaged to obtain a canopy scale value. We then use these values to calculate $\phi$ and $q$, by assuming that assimilation is zero at a light level equal to the compensation point $C_{\text {direct }}$.

We use our posterior age distributions to correct photosynthetic rates for the effects of leaf ageing. Studies have shown (Kitajima et al., 1997; Doughty and Goulden, 2008) that in tropical systems photosynthesis rates peak a few weeks after budburst and that measured rates decline with age, reaching half the peak value for leaves older than 1 year. Of course, these figures do not reflect the large variation in leaf lifespan in the Amazon. It has been observed that longer lived leaves show a slower decline in assimilation rates with age and are also slower to reach peak rates (Kitajima et al., 1997).

To account for these changes we use an age correction factor. Assuming that the values defined above are correct for mature leaves, then a population composed entirely of mature foliage will have an age factor of 1 , while populations with a combination of young, mature and old leaves will have a factor less than 1 . We define this factor as

$\gamma_{\text {age }}=f_{\text {new }} A_{\text {new }}+f_{\text {mat }} A_{\text {mat }}+f_{\text {old }} A_{\text {old }}$,

where $f_{\text {new }}, f_{\text {mat }}$ and $f_{\text {old }}$ are the fractions of young (age $<0.07 \tau_{95}$ ), mature and old (age $>$ age $_{\min }$ ) leaves respectively. The corresponding adjusting factors are equal to 0.05 for young leaves, 1 for mature and 0.5 for old. We assume that the $A_{\max }$ and $I_{\max }$ values used above are valid for fully mature leaves.

\section{Appendix D}

\section{Predicted leaf litterfall}

We compare model predictions against ground-based measurements of leaf litterfall 9Table A1. This provides an evaluation of the model parameters that is independent of the LAI data used to parameterise the model. All litterfall measurements have been converted from mass units $\left(\mathrm{gm}^{-2}\right.$ month $^{-1}$ ) to area units $\left(\mathrm{m}^{2} \mathrm{~m}^{-2}\right.$ month $\left.^{-1}\right)$ using either the leaf mass per unit area value given by (Fyllas et al., 2009) $\left(94.85 \mathrm{gm}^{-2}\right)$ or the specific value for that site if any is given in the study (mentioned in brackets).

Acknowledgements. This project was funded through a Microsoft Research studentship. We would like to thank the developers of the MODIS LAI product for providing the data that forms the basis for our work. We would also like to thank our colleague Prof. Roy Thompson for comments on the manuscript.

Edited by: X. Wang

\section{References}

Aragão, L., Shimabukuro, Y. E., Santo, F., and Williams, M.: Landscape pattern and spatial variability of leaf area index in Eastern Amazonia, Forest Ecol. Manag., 211, 240-256, 2005.

Aragão, L. E. O. C., Malhi, Y., Metcalfe, D. B., Silva-Espejo, J. E., Jiménez, E., Navarrete, D., Almeida, S., Costa, A. C. L., Salinas, N., Phillips, O. L., Anderson, L. O., Alvarez, E., Baker, T. R., Goncalvez, P. H., Huamán-Ovalle, J., Mamani-Solórzano, M., Meir, P., Monteagudo, A., Patiño, S., Peñuela, M. C., Prieto, A., Quesada, C. A., Rozas-Dávila, A., Rudas, A., Silva Jr., J. A., and Vásquez, R.: Above- and below-ground net primary productivity across ten Amazonian forests on contrasting soils, Biogeosciences, 6, 2759-2778, doi:10.5194/bg-6-2759-2009, 2009.

Arora, V. K. and Boer, G. J.: A parameterization of leaf phenology for the terrestrial ecosystem component of climate models, Glob. Change Biol., 11, 39-59, 2005.

Asner, G. P. and Alencar, A.: Drought impacts on the Amazon forest: the remote sensing perspective, New Phytol., 187, 569-578, doi:10.1111/j.1469-8137.2010.03310.x, http://dx.doi. org/10.1111/j.1469-8137.2010.03310.x, 2010.

Barkley, M. P., Palmer, P. I., De Smedt, I., Karl, T., Guenther, A., and Van Roozendael, M.: Regulated large-scale annual shutdown of Amazonian isoprene emissions?, Geophys. Res. Lett., 36, L04803, doi:10.1029/2008GL036843, 2009.

Bey, I., Jacob, D., Yantosca, R., Logan, J., Field, B., Fiore, A., Li, Q., Liu, H., Mickley, L., and Schultz, M.: Global modeling of tropospheric chemistry with assimilated meteorology: Model description and evaluation, J. Geophys. Res., 106, 23073-23095, 2001.

Bonal, D., Bosc, A., Ponton, S., Goret, J.-Y., Burban, B., Gross, P., Bonnefond, J.-M., Elbers, J., Longdoz, B., Epron, D., Guehl, J.-M., and Granier, A.: Impact of severe dry season on net ecosystem exchange in the Neotropical rainforest of French Guiana, Glob. Change Biol., 14, 1917- 
1933, doi:10.1111/j.1365-2486.2008.01610.x, http://dx.doi.org/ 10.1111/j.1365-2486.2008.01610.x, 2008.

Bounoua, L., Hall, F. G., Sellers, P. J., Kumar, A., Collatz, G. J., Tucker, C. J., and Imhoff, M. L.: Quantifying the negative feedback of vegetation to greenhouse warming: A modeling approach, Geophys. Res. Lett., 37, L23701, http://dx.doi.org/10. 1029/2010GL045338, 2010.

Brando, P. M., Goetz, S. J., Baccini, A., Nepstad, D. C., Beck, P. S. A., and Christman, M. C.: Seasonal and interannual variability of climate and vegetation indices across the Amazon, Proceedings of the National Academy of Sciences, 107, 14 685-14 690, doi:10.1073/pnas.0908741107, http://www.pnas. org/content/107/33/14685.abstract, 2010.

Chave, J., Navarrete, D., Almeida, S., Álvarez, E., Aragão, L. E. O. C., Bonal, D., Châtelet, P., Silva-Espejo, J. E., Goret, J.-Y., von Hildebrand, P., Jiménez, E., Patiño, S., Peñuela, M. C., Phillips, O. L., Stevenson, P., and Malhi, Y.: Regional and seasonal patterns of litterfall in tropical South America, Biogeosciences, 7, 43-55, doi:10.5194/bg-7-43-2010, 2010.

Cohen, W. B., Maiersperger, T. K., Turner, D. P., Ritts, W. D., Pflugmacher, D., Kennedy, R. E., Kirschbaum, A., Running, S. W., Costa, M., and Gower, S. T.: MODIS land cover and LAI collection 4 product quality across nine sites in the western hemisphere, IEEE T. Geosci. Remote., 44, 1843-1857, 2006.

Cramer, W., Bondeau, A., Woodward, F., Prentice, I., Betts, R., Brovkin, V., Cox, P., Fisher, V., Foley, J., Friend, A., Kucharik, C., Lomas, M., Ramankutty, N., Sitch, S., Smith, B., White, A., and Young-Molling, C.: Global response of terrestrial ecosystem structure and function to $\mathrm{CO}_{2}$ and climate change: results from six dynamic global vegetation models, Glob. Change. Biol., 7, 357-373, 2001.

da Rocha, H. R., Goulden, M. L., Miller, S. D., Menton, M. C., Pinto, L., de Freitas, H. C., and Figueira, A.: Seasonality of water and heat fluxes over a tropical forest in eastern Amazonia, Ecol. Appl., 14, S22-S32, 2004.

Dezzeo, N. and Chacon, N.: Litterfall and nutrient input in undisturbed and adjacent fire disturbed forests of the Gran Sabana, Southern Venezuela, Interciencia, 31, 894-899, 2006.

Doughty, C. E. and Goulden, M. L.: Seasonal patterns of tropical forest leaf area index and $\mathrm{CO}_{2}$ exchange, J. Geophys. Res., 113, doi:10.1029/2007JG000590, 2008.

Fyllas, N. M., Patiño, S., Baker, T. R., Bielefeld Nardoto, G., Martinelli, L. A., Quesada, C. A., Paiva, R., Schwarz, M., Horna, V., Mercado, L. M., Santos, A., Arroyo, L., Jiménez, E. M., Luizão, F. J., Neill, D. A., Silva, N., Prieto, A., Rudas, A., Silviera, M., Vieira, I. C. G., Lopez-Gonzalez, G., Malhi, Y., Phillips, O. L., and Lloyd, J.: Basin-wide variations in foliar properties of Amazonian forest: phylogeny, soils and climate, Biogeosciences, 6 , 2677-2708, doi:10.5194/bg-6-2677-2009, 2009.

Gelman, A.: Bayesian data analysis, Texts in statistical science, Chapman \& Hall, Boca Raton; London, 2 Edn., 2004.

Gilks, W. R.: Markov chain Monte Carlo in practice, edited by: Gilks, W. R., Richardson, S., and Spiegelhalter, D. J., 1996.

Goulden, M. L., Miller, S. D., da Rocha, H. R., Menton, M. C., de Freitas, H. C., Figueira, A., and de Sousa, C. A. D.: Diel and seasonal patterns of tropical forest $\mathrm{CO}_{2}$ exchange, Ecol. Appl., 14, S42-S54, 2004.

Graham, E. A., Mulkey, S. S., Kitajima, K., Phillips, N. G., and Wright, S. J.: Cloud cover limits net $\mathrm{CO}_{2}$ uptake and growth of a rainforest tree during tropical rainy seasons, Proc. Natl. Acad. Sci., 100, 572-576, doi:10.1073/pnas.0133045100, http://www. pnas.org/content/100/2/572.abstract, 2003.

Harper, A. B., Denning, A. S., Baker, I. T., Branson, M. D., Prihodko, L., and Randall, D. A.: Role of deep soil moisture in modulating climate in the Amazon rainforest, Geophys. Res. Lett., 37, L05802, 2010.

Hayden, B. P.: Ecosystem feedbacks on climate at the landscape scale, Philos. T. R. Soc. Lond., 353, 5-18, doi:10.1098/rstb.1998.0186, http://rstb.royalsocietypublishing. org/content/353/1365/5.abs\%tract, 1998.

Hijmans, R., Cameron, S., Parra, J., Jones, P., and Jarvis, A.: Very high resolution interpolated climate surfaces for global land areas, Int. J. Climatol., 25, 1965-1978, 2005.

Huete, A. R., Didan, K., Shimabukuro, Y. E., Ratana, P., Saleska, S. R., Hutyra, L. R., Yang, W. Z., Nemani, R. R., and Myneni, R.: Amazon rainforests green-up with sunlight in dry season, Geophys. Res. Lett., 33, doi:10.1029/2005GL025583, 2006.

Hutyra, L. R., Munger, J. W., Saleska, S. R., Gottlieb, E., Daube, B. C., Dunn, A. L., Amaral, D. F., de Camargo, P. B., and Wofsy, S. C.: Seasonal controls on the exchange of carbon and water in an Amazonian rain forest, J. Geophys. Res.-Biogeo., 112, doi:10.1029/2006JG000365, 2007.

Jipp, P. H., Nepstad, D. C., Cassel, D. K., and Reis De Carvalho, C.: Deep Soil Moisture Storage and Transpiration in Forests and Pastures of Seasonally-Dry Amazonia, Climatic Change, 39, 395-412, http://dx.doi.org/10.1023/A: 1005308930871, doi:10.1023/A:1005308930871, 1998.

Kalnay, E., Kanamitsu, M., Kistler, R., Collins, W., Deaven, D., Gandin, L., Iredell, M., Saha, S., White, G., Woollen, J., Zhu, Y., Chelliah, M., Ebisuzaki, W., Higgins, W., Janowiak, J., Mo, K., Ropelewski, C., Wang, J., Leetmaa, A., Reynolds, R., Jenne, R., and Joseph, D.: The NCEP/NCAR 40-year reanalysis project, Bull. Am. Meteorol. Soc., 77, 437-471, 1996.

Kitajima, K., Mulkey, S., and Wright, S.: Decline of photosynthetic capacity with leaf age in relation to leaf longevities for five tropical canopy tree species, Am. J. Botan., 84, 702-708, 1997.

Knyazikhin, Y., Miessen, G., Panfyorov, O., and Gravenhorst, G.: Small-scale study of three-dimensional distribution of photosynthetically active radiation in a forest, Agr. Forest Meteorol., 88, 215-239, 1997.

Knyazikhin, Y., J., G., Privette, J. L., Tian, Y., Lotsch, A., Zhang., Y., Wang, Y., Morisette, J. T., P.Votava, Myneni, R., Nemani, R. R., and Running, S. W.: MODIS Leaf Area Index (LAI) and Fraction of Photosynthetically Active Radiation Absorbed by Vegetation (FPAR) Product (MOD15) Algorithm Theoretical Basis Document, http://eospso.gsfc.nasa.gov/atbd/modistables, 1999.

Korner, C. and Basler, D.: Phenology Under Global Warming, Science, 327, 1461-1462, doi:10.1126/science.1186473, http: //www.sciencemag.org, 2010.

Kubiske, M. and Pregitzer, K.: Effects of elevated $\mathrm{CO}_{2}$ and light availability on the photosynthetic light response of trees of contrasting shade tolerance, Tree Physiol., 16, 351-358, 1996.

Langenheim, J., Osmond, C., Brooks, A., and Ferrar, P.: Photosynthetic responses to light in seedlings of selected Amazonian and Australian rainforest tree species, Oecologia, 63, 215-224, 1984.

Lips, J. M. and Duivenvoorden, J. F.: Fine litter input to terrestrial humus forms in Colombian amazonia, Oecologia, 108, 138-150, 
1996.

Malhado, A. C. M., Costa, M. H., de Lima, F. Z., Portilho, K. C., and Figueiredo, D. N.: Seasonal leaf dynamics in an Amazonian tropical forest, Forest Ecol. Manag., 258, 1161-1165, 2009.

Malhi, Y. and Grace, J.: Tropical forests and atmospheric carbon dioxide, Trends Ecol Evol, 15, 332337, doi:10.1016/S0169-5347(00)01906-6, http://www. sciencedirect.com/science/article/B6VJ1-40RSGFC-K/\%2/ 4d3875b9b3882ec9d060a675b016ff41, 2000.

Malhi, Y., Nobre, A. D., Grace, J., Kruijt, B., Pereira, M. G. P., Culf, A., and Scott, S.: Carbon dioxide transfer over a Central Amazonian rain forest, J. Geophys. Res., 103, 31593-31612, http://dx.doi.org/10.1029/98JD02647, 1998.

McDowell, N., Pockman, W. T., Allen, C. D., Breshears, D. D., Cobb, N., Kolb, T., Plaut, J., Sperry, J., West, A., Williams, D. G., and Yepez, E. A.: Mechanisms of plant survival and mortality during drought: why do some plants survive while others succumb to drought?, New Phytol., 178, 719739, doi:10.1111/j.1469-8137.2008.02436.x, http://dx.doi.org/ 10.1111/j.1469-8137.2008.02436.x, 2008.

Meir, P., Grace, J., and Miranda, A. C.: Photographic method to measure the vertical distribution of leaf area density in forests, Agricultural and Forest Meteorology, 102, 105-111, doi:10.1016/S0168-1923(00)00122-2, http: //www.sciencedirect.com/science/article/B6V8W-4007P2P-3/ \%2/a926c21c4ceb866d3ee12536a4df4869, 2000.

Miranda, E., Vourlitis, G., Priante, N., Priante, P., Campelo, J., Suli, G., Fritzen, C., Lobo, F., and Shiraiwa, S.: Seasonal variation in the leaf gas exchange of tropical forest trees in the rain forestsavanna transition of the southern Amazon Basin, J. Trop. Ecol., 21, 451-460, doi:10.1017/S0266467405002427, 2005.

Myneni, R. B., Yang, W. Z., Nemani, R. R., Huete, A. R., Dickinson, R. E., Knyazikhin, Y., Didan, K., Fu, R., Juarez, R. I. N., Saatchi, S. S., Hashimoto, H., Ichii, K., Shabanov, N. V., Tan, B., Ratana, P., Privette, J. L., Morisette, J. T., Vermote, E. F., Roy, D. P., Wolfe, R. E., Friedl, M. A., Running, S. W., Votava, P., ElSaleous, N., Devadiga, S., Su, Y., and Salomonson, V. V.: Large seasonal swings in leaf area of Amazon rainforests, Proc. Natl. Acad. Sci. USA, 104, 4820-4823, 2007.

Nepstad, D. C., de Carvalho, C. R., Davidson, E. A., Jipp, P. H., Lefebvre, P. A., Negreiros, G. H., da Silva, E. D., Stone, T. A., Trumbore, S. E., and Vieira, S.: The role of deep roots in the hydrological and carbon cycles of Amazonian forests and pastures, Nature, 372, 666-669, http://dx.doi.org/10.1038/ $372666 \mathrm{a} 0,1994$.

Osada, N., Takeda, H., Furukawa, A., and Awang, M.: Leaf Dynamics and Maintenance of Tree Crowns in a Malaysian Rain Forest Stand, J. Ecol., 89, 774-782, http://www.jstor.org/stable/ 3072151, 2001.

Phillips, O. L., Aragão, L. E. O. C., Lewis, S. L., Fisher, J. B., Lloyd, J., Lopez-Gonzalez, G., Malhi, Y., Monteagudo, A., Peacock, J., Quesada, C. A., van der Heijden, G., Almeida, S., Amaral, I., Arroyo, L., Aymard, G., Baker, T. R., Banki, O., Blanc, L., Bonal, D., Brando, P., Chave, J., de Oliveira, A. C. A., Cardozo, N. D., Czimczik, C. I., Feldpausch, T. R., Freitas, M. A., Gloor, E., Higuchi, N., Jimenez, E., Lloyd, G., Meir, P., Mendoza, C., Morel, A., Neill, D. A., Nepstad, D., Patino, S., Penuela, M. C., Prieto, A., Ramirez, F., Schwarz, M., Silva, J., Silveira, M., Thomas, A. S., Steege, H. t., Stropp, J., Vasquez, R., Zelazowski,
P., Davila, E. A., Andelman, S., Andrade, A., Chao, K.-J., Erwin, T., Di Fiore, A., C, E. H., Keeling, H., Killeen, T. J., Laurance, W. F., Cruz, A. P., Pitman, N. C. A., Vargas, P. N., RamirezAngulo, H., Rudas, A., Salamao, R., Silva, N., Terborgh, J., and Torres-Lezama, A.: Drought Sensitivity of the Amazon Rainforest, Science, 323, 1344-1347, 2009.

Reich, P. B., Uhl, C., Walters, M. B., Prugh, L., and Ellsworth, D. S.: Leaf demography and phenology in Amazonian rain forest: A census of 40000 leaves of 23 tree species, Ecol. Monogr., 74, 3-23, 2004.

Riddoch, I., Lehto, T., and Grace, J.: Photosynthesis of Tropical Tree Seedlings in Relation to Light and Nutrient Supply, New Phytol, 119, 137-147, http://www.jstor.org/stable/2557718, 1991.

Roberts, J., Cabral, O., Costa, J., da, P., McWilliam, A.-L., Sa', T., and de, A.: Amazonian Deforestation and Climate, chap. An overview of the leaf area index and physiological measurements during ABRACOS, 287-306, John Wiley \& Sons, Chichester, 1996.

Saleska, S. R., Didan, K., Huete, A. R., and da Rocha, H. R.: Amazon forests green-up during 2005 drought, Science, 318, 612612, 2007.

Samanta, A., Ganguly, S., Hashimoto, H., Devadiga, S., Vermote, E., Knyazikhin, Y., Nemani, R. R., and Myneni, R. B.: Amazon forests did not green-up during the 2005 drought, Geophys. Res. Lett., 37, L05401, doi:10.1029/2009GL042154, 2010.

Samanta, A., Knyazikhin, Y., Xu, L., Dickinson, R. E., Fu, R., Costa, M. H., Saatchi, S. S., Nemani, R. R., and Myneni, R. B.: Seasonal changes in leaf area of Amazon forests from leaf flushing and abscission, J. Geophys. Res., 117, G01015, http://dx.doi.org/10.1029/2011JG001818, 2012.

Sanches, L., Valentini, C. M. A., JÃ ${ }^{\circ}$ nior, O. B. P., Nogueira, J. d. S., Vourlitis, G. L., Biudes, M. S., da Silva, C. J., Bambi, P., and Lobo, F. d. A.: Seasonal and interannual litter dynamics of a tropical semideciduous forest of the southern Amazon Basin, Brazil, J. Geophys. Res., 113, doi:10.1029/2007JG000593, 2008.

Schwartz, M. D.: Advancing to full bloom: planning phenological research for the 21st century, Int. J. Biometeorol., 42, 113-118, 1999.

Sharpe, J.: Leaf growth and demography of the rheophytic fern Thelypteris angustifolia (Willdenow) Proctor in a Puerto Rican rainforest, Plant. Ecol., 130, 203-212, 1997.

Sombroek, W.: Spatial and temporal patterns of Amazon rainfall Consequences for the planning of agricultural occupation and the protection of primary forests, Ambio, 30, 388-396, 2001.

Sombroek, W., Fearnside, P., and Cravo, M.: Geographic assessment of carbon stored in Amazonian terrestrial ecosystems and their soils in particular, in: Global Climate Change and Tropical Ecosystems, edited by Lal, R and Kimble, JM and Stewart, BA, 375-389, CRC PRESS-TAYLOR \& FRANCIS GROUP, Boca Raton, 2000.

White, M. A., Running, S. W., and Thornton, P. E.: The impact of growing-season length variability on carbon assimilation and evapotranspiration over 88 years in the eastern US deciduous forest, Int. J. Biometeorol., 42, 139-145, http://dx.doi.org/10.1007/ s004840050097, doi:10.1007/s004840050097, 1999.

Wilson, K. B. and Baldocchi, D. D.: Seasonal and interannual variability of energy fluxes over a broadleaved temperate deciduous forest in North America, Agr. Forest Meteo- 
rol., 100, 1-18, doi:10.1016/S0168-1923(99)00088-X, http: //www.sciencedirect.com/science/article/B6V8W-3Y9G9YN-1/ \%2/a64d3b46065d636190187ce3df2a333a, 2000.

Wright, S. J. and Vanschaik, C. P.: Light and the Phenology of Tropical Trees, Am. Nat., 143, 192-199, 1994.
Yang, W. Z., Tan, B., Huang, D., Rautiainen, M., Shabanov, N. V., Wang, Y., Privette, J. L., Huemmrich, K. F., Fensholt, R., Sandholt, I., Weiss, M., Ahl, D. E., Gower, S. T., Nemani, R. R., Knyazikhin, Y., and Myneni, R. B.: MODIS leaf area index products: From validation to algorithm improvement, IEEE T. Geosci. Remote., 44, 1885-1898, 2006. 